\title{
Prognostic Relevance of Discordant Results Between Fractional Flow Reserve and Resting Indices
}

\author{
Takashi Kubo, MD, PhD; Yasutsugu Shiono, MD, PhD
}

$\mathbf{F}$ ractional flow reserve (FFR) is an established physiologic index of coronary stenosis. ${ }^{1-5}$ The DEFER trial (Deferral vs. performance of percutaneous coronary intervention of functionally non-significant coronary stenosis) showed that outcome after deferral of revascularization of an intermediate coronary stenosis based on FFR was excellent. ${ }^{6}$ FFR is measured by intracoronary pressure guidewire during maximal hyperemia. Recently, instantaneous wave-free ratio (iFR), resting distal to aortic coronary pressure (resting $\mathrm{Pd} / \mathrm{Pa}$ ), resting full-cycle ratio (RFR), and diastolic pressure ratio (dPR) have emerged as resting physiologic indices that do not require the pharmacological induction of maximal hyperemia (Figure). To date, several studies have demonstrated good correlations and agreements between FFR and these resting indices. Moreover, especially in iFR, the DEFINE-FLAIR trial (Functional lesion assessment of intermediate stenosis to guide revascularisation) and the iFR-SWEDEHEART trial (Instantaneous wave-free ratio versus fractional flow reserve in patients with stable angina pectoris or acute

\begin{abstract}
Article p 2210
coronary syndrome) revealed that iFR was non-inferior to FFR for guiding deferral of revascularization with respect to clinical outcomes. ${ }^{7,8}$ The current ESC/EACTS Guidelines on myocardial revascularization define both FFR and iFR equally as Class IA to assess the hemodynamic relevance of intermediate-grade stenosis. ${ }^{9}$ Because the resting indices can be measured easily and less invasively compared with FFR, their use is rapidly increasing. However, it is not rare to have discordant results between FFR and the resting indices, which can create confusion about the treatment strategy. It is a serious clinical problem if a necessary revascularization is deferred or an unnecessary revascularization is performed in a patient with discordant results.

In this issue of the Journal, Lee et a ${ }^{10}$ report 2-year clinical outcomes of coronary lesions deferred from revascularization because of discordant results between FFR and resting indices such as iFR, resting $\mathrm{Pd} / \mathrm{Pa}, \mathrm{RFR}$, and
\end{abstract}

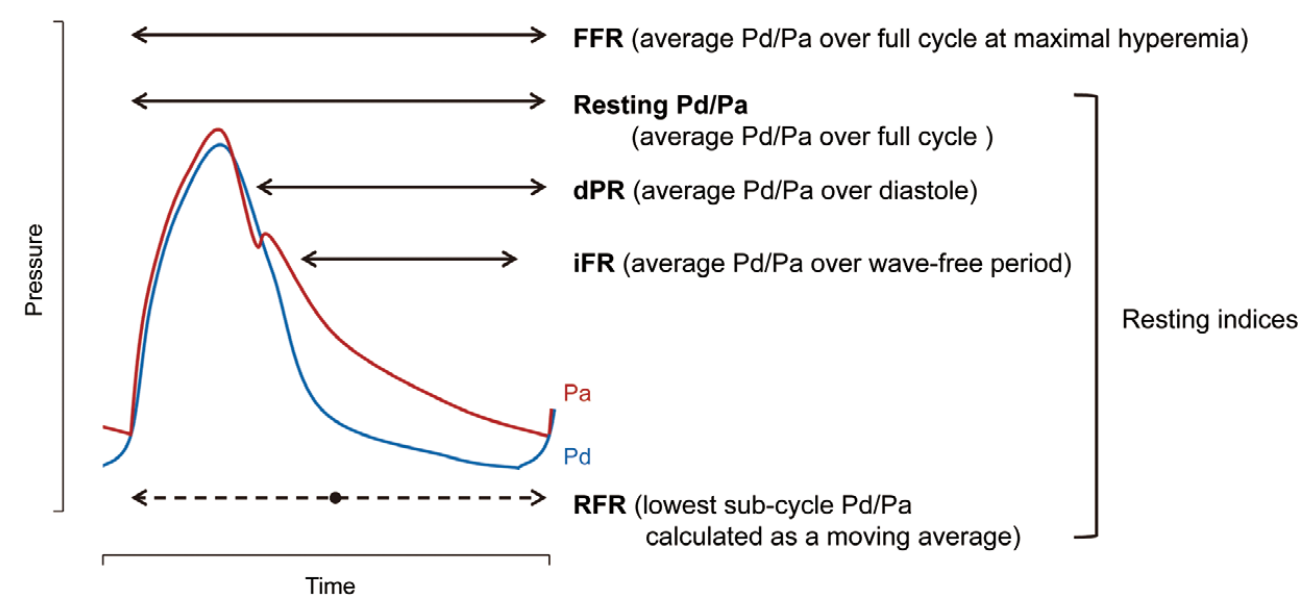

Figure. Fractional flow reserve (FFR) and resisting indices. The time phase for measurement in a cardiac cycle is different among these physiological indices. dPR, diastolic pressure ratio; iFR, instantaneous wave-free ratio; $\mathrm{Pa}$, aortic pressure; Pd, distal coronary pressure; RFR, resting full-cycle ratio.

The opinions expressed in this article are not necessarily those of the editors or of the Japanese Circulation Society.

Received August 20, 2019; accepted August 20, 2019; J-STAGE Advance Publication released online September 10, 2019

Department of Cardiovascular Medicine, Wakayama Medical University, Wakayama, Japan

Mailing address: Takashi Kubo, MD, PhD, FJCS, Department of Cardiovascular Medicine, Wakayama Medical University, 811-1

Kimiidera, Wakayama 641-8509, Japan. E-mail: takakubo@wakayama-med.ac.jp

ISSN-1346-9843 All rights are reserved to the Japanese Circulation Society. For permissions, please e-mail: cj@j-circ.or.jp 
dPR. The authors show that the incidence of coronary events (comprising cardiac death, target vessel-related myocardial infarction and target vessel-related ischemiadriven revascularization) was similarly low in the groups with normal FFR and abnormal resting index, abnormal FFR and normal resting index, and normal FFR and normal resting index, which suggests that deferral of revascularization is a possible option for lesions with discordant results between FFR and the resting indices.

The prognostic relevance of discordant results between FFR and the resting indices in patients with deferral of revascularization is controversial. A post-hoc analysis of DEFINE-FLAIR trial showed that patients with left anterior descending artery lesions in whom iFR-guided deferral was performed had significantly lower event rates than those with FFR-guided deferral.11 Also, an analysis in the merged populations of the DEFINE-FLAIR trial and the iFR-SWEDEHEART trial demonstrated that when using iFR rather than FFR, the lesion was deferred more frequently from revascularization without increasing the risk of coronary events. ${ }^{12}$ Those 2 studies consistently suggested the possible superiority of iFR-guidance in deferral of revascularization compared with FFR-guidance. In contrast, a substudy of the DEFINE-FLAIR trial showed that there was no difference in the risk of coronary events after deferral of revascularization between FFR and iFR in a diabetes population. ${ }^{13}$ In line with that previous substudy, the study by Lee et al suggest comparable safety between FFR and iFR in guiding the deferral of revascularization. ${ }^{\mathbf{1 0}}$

Some possible mechanisms of the difference in prognostic value between FFR and iFR have been proposed. Compared with FFR, iFR shows better agreement with coronary flow reserve (CFR). ${ }^{\mathbf{1 4}}$ Therefore, abnormal CFR, a powerful predictor of coronary events, may be less frequently seen in lesions deferred from revascularization with normal iFR compared with normal FFR. This may explain the superiority of iFR-guidance for deferral of revascularization. On the other hand, FFR, but not iFR, is potentially associated with the presence of vulnerable plaques, because the vasodilatory ability at maximum hyperemia is impaired in such lesions ${ }^{\mathbf{1 5}}$ and suggests that FFR may be more sensitive for detecting high-risk lesions.

The prognostic value of resting indices other than iFR has not been fully investigated. Importantly, the study by Lee et al showed that discordant results not only between FFR and iFR but also between FFR and other resting indices such as resting $\mathrm{Pd} / \mathrm{Pa}, \mathrm{RFR}$, and $\mathrm{dPR}$ were not associated with increased risk of coronary events after deferral of revascularization. ${ }^{\mathbf{1 0}}$ If the differences in measurement algorithm among the physiologic indices have no effect on patient prognosis, resting $\mathrm{Pd} / \mathrm{Pa}, \mathrm{RFR}$, and $\mathrm{dPR}$ can be used interchangeably with iFR. The results of the study by Lee et al $^{10}$ will help to extend the clinical recommendations of FFR and iFR to other resting indices and accelerate the replacement of FFR with simpler and less invasive resting indices in daily clinical practice.

\section{Financial / Nonfinancial Disclosures}

T.K. has received lecture fees from Abbott Vascular. Y.S. has received lecture fees from Philips.

\section{References}

1. Kubo T, Takahata M, Terada K, Mori K, Arita Y, Ino Y, et al. Retrospective comparison of long-term clinical outcomes between percutaneous coronary intervention and medical therapy in stable coronary artery disease with gray zone fractional flow reserve: COMFORTABLE retrospective study. Circ J 2018; 82: 30443051 .

2. ShionoY, Kubo T, Tanaka A, Ino Y, Yamaguchi T, Tanimoto $\mathrm{T}$, et al. Long-term outcome after deferral of revascularization in patients with intermediate coronary stenosis and gray-zone fractional flow reserve. Circ $J$ 2015; 79: 91-95.

3. Kubo T, Emori H, Katayama Y, Terada K. Three-vessel fractional flow reserve measurement for predicting clinical prognosis in patients with coronary artery disease. $J$ Thorac Dis 2018; 10: S3115-S3120.

4. Shiono Y, Matsuo H, Kawasaki T, Amano T, Kitabata H, Kubo $\mathrm{T}$, et al. The clinical impact of coronary computed tomography angiography-derived fractional flow reserve on Japanese population in the ADVANCE Registry. Circ J 2019; 83: 1293-1301.

5. Emori H, Kubo T, Kameyama T, Ino Y, Matsuo Y, Kitabata H, et al. Diagnostic accuracy of quantitative flow ratio for assessing myocardial ischemia in prior myocardial infarction. Circ J 2018; 82: $807-814$.

6. Zimmermann FM, Ferrara A, Johnson NP, van Nunen LX, Escaned J, Albertsson P, et al. Deferral vs. performance of percutaneous coronary intervention of functionally non-significant coronary stenosis: 15-year follow-up of the DEFER trial. Eur Heart $J$ 2015; 36: 3182-3188.

7. Davies JE, Sen S, Dehbi HM, Al-Lamee R, Petraco R, Nijjer SS, et al. Use of the instantaneous wave-free ratio or fractional flow reserve in PCI. N Engl J Med 2017; 376: 1824-1834.

8. Götberg M, Christiansen EH, Gudmundsdottir IJ, Sandhall L, Danielewicz M, Jakobsen L, et al. Instantaneous wave-free ratio versus fractional flow reserve to guide PCI. N Engl J Med 2017; 376: $1813-1823$.

9. Neumann FJ, Sousa-Uva M, Ahlsson A, Alfonso F, Banning AP, Benedetto U, et al. 2018 ESC/EACTS Guidelines on myocardial revascularization. Eur Heart $J$ 2019; 40: 87-165.

10. Lee JM, Rhee TM, Choi KH, Park J, Hwang D, Kim J, et al. Clinical outcome of lesions with discordant results among different invasive physiologic indices: Resting distal coronary to aortic pressure ratio, resting full-cycle ratio, diastolic pressure ratio, instantaneous wave-free ratio, and fractional flow reserve. Circ $J$ 2019; 83: 2210-2221.

11. Sen S, Ahmad Y, Dehbi HM, Howard JP, Iglesias JF, Al-Lamee $\mathrm{R}$, et al. Clinical events after deferral of LAD revascularization following physiological coronary assessment. J Am Coll Cardiol 2019; 73: 444-453.

12. Escaned J, Ryan N, Mejia-Renteria H, Cook CM, Dehbi HM, Alegria-Barrero E, et al. Safety of the deferral of coronary revascularization on the basis of instantaneous wave-free ratio and fractional flow reserve measurements in stable coronary artery disease and acute coronary syndromes. JACC Cardiovasc Interv 2018; 11: 1437-1449.

13. DEFINE-FLAIR Trial Investigators, Lee JM, Choi KH, Koo BK, Dehbi HM, Doh JH, Nam CW, et al. Comparison of major adverse cardiac events between instantaneous wave-free ratio and fractional flow reserve-guided strategy in patients with or without type 2 diabetes: A secondary analysis of a randomized clinical trial. JAMA Cardiol 2019; 4: 857-864.

14. Petraco R, van de Hoef TP, Nijjer S, Sen S, van Lavieren MA, Foale RA, et al. Baseline instantaneous wave-free ratio as a pressure-only estimation of underlying coronary flow reserve: Results of the JUSTIFY-CFR Study (Joined coronary pressure and flow analysis to determine diagnostic characteristics of basal and hyperemic indices of functional lesion severity-coronary flow reserve). Circ Cardiovasc Interv 2014; 7: 492-502.

15. Ahmadi A, Stone GW, Leipsic J, Serruys PW, Shaw L, Hecht H, et al. Association of coronary stenosis and plaque morphology with fractional flow reserve and outcomes. JAMA Cardiol 2016; 1: $350-357$. 